\title{
"Caracterización de tres beneficios húmedos colectivos y uno industrializado en la Unión de Cooperativas Agropecuarias del Norte UCANOR, Jinotega"
}

\author{
Pichardo, Claudio; Reyes, Oscar; Romero, Freddy
}

\section{Resumen}

En la cosecha 2010 - 2011 fueron caracterizados tres beneficios húmedos colectivos y uno industrializado en el departamento de Jinotega. Dicho estudio contó con el apoyo técnico y financiero de FUNICA, y la participación de la Unión de Cooperativas Agropecuarias del Norte, UCANOR. La investigación se realizó con la finalidad de caracterizar los beneficios colectivos en relación a los tradicionales para identificar sus limitaciones en cuanto a estructuras, equipos, tecnologías utilizadas y manejo del café en finca. Se estudió generalidades de cada uno de los beneficios húmedos de manera individual, aspectos de estructuras, productividad, gastos de agua, cantidad de desechos y el tratamiento de los mismos. Los beneficios colectivos caracterizados son de tipo familiar, con capacidad de procesamiento variada entre 2,045 a 9,545 kg de café en un día pico de trabajo, las estructuras de estos beneficios son de metal, concreto y madera. En el beneficio industrializado la capacidad de procesamiento de un día pico es de 9000 qq de café uva (equivalente a 409,090.90 kg), la estructura de este beneficio es de concreto, con cinco despulpadoras las cuales estaban ubicadas en serie lo que permite que se procese una buena cantidad de café. Los beneficios tradicionales y los industrializados, producen desechos sólidos y líquidos provocando impacto al medio ambiente al afectar los suelos y ecosistemas acuáticos debido a la forma tradicional de manejo de desechos. La información resultante de esta investigación será de utilidad para la presentación de un modelo de beneficio ecológico colectivo, para garantizar menor consumo de agua y reducir en menor proporción la contaminación ambiental.

Palabras clave: beneficios colectivos, beneficios industrializados, contaminación.

\section{Introducción}

La recolección del fruto del café es el inicio del proceso de beneficiado. Su calidad está influenciada por las prácticas agronómicas aplicadas en la finca, así como por la disponibilidad y tipo de mano de obra que se dedique a la recolección o corte; se deben de cortar únicamente los frutos maduros ya que de éstos se obtiene una buena calidad de café. Los frutos verdes, sobre maduros, secos, enfermos se deben de separar y beneficiarlos por la vía seca (IICA, 2008).

Al respecto, el café se recibe directamente de los corteros utilizando medidas de peso o de volumen según las costumbres regionales. En beneficios pequeños la cereza es depositada en pequeñas tolvas. En la medida que se incrementan los volúmenes de café es necesario aumentar el tamaño de las tolvas (IICA, 2008). 
Según (Dicovskiy L. M., 2009), en un estudio realizado en San Rafael del Norte el estado de los beneficios según la apreciación de sus dueños es $50 \%$ regular, $33 \%$ bueno y un $17 \%$ malo. La ubicación de estos es principalmente a menos de 100 metros de las viviendas (72\%), ríos y quebradas $(29 \%)$, lo cual debe ser tomado en cuenta para las actividades dirigidas a prevenir la contaminación ambiental.

Con esta investigación se caracterizó de manera productiva y ambiental cuatro modelos de beneficios húmedos existentes de los socios de la Unión de Cooperativas Agropecuarias del Norte-UCANOR de Jinotega. De los cuatro modelos evaluados, tres son modelos colectivos de pequeños y medianos productores y un modelo industrializado. Una vez ofrecida la caracterización de los beneficios húmedos de café se ofrecen una serie de opciones de mejora que al implementarlas podrían beneficiar a los productores.

\section{Materiales y métodos}

El estudio se realizó en el departamento de Jinotega en las comunidades Santo Domingo de Asturias, La Vencedora 1, 2 y San Francisco de los Cedros, en las fincas de productores asociados a la Unión de Cooperativas Agropecuarias del Norte (UCANOR).

La investigación realizada, inició con visitas a fincas productoras de café pertenecientes a la Cooperativa UCANOR, seguidamente se hizo una observación directa del proceso de beneficiado húmedo, esto permitió conocer el estado actual de los beneficios y su variabilidad general.

La información se recolectó a través de entrevistas, observación directa a los beneficios de productores de las finca de café y miembros de la cooperativa UCANOR, Jinotega", así como la realización de cálculos de producción del beneficiado.

Se evaluó cada uno de los indicadores seleccionados, basándose en los resultados de la entrevista, observación, información disponible, mediciones y análisis de campo, para el análisis ambiental se realizó mediante una serie de matrices, que permitió medir de acuerdo al grado del impacto un valor ponderado.

\section{Resultados y discusión}

\section{Caracterización del beneficio Países Bajos}

La Finca "Países Bajos" está ubicada en la Comunidad Santo Domingo de Asturias y tiene las variedades de café Caturra y Caturra Estrella. El tipo de beneficio es colectivo y pertenece a la cooperativa "El progreso". Esta finca se encuentra a 1005 msnm con un área total de beneficio de $140 \mathrm{~m} 2$.

El beneficio tiene una capacidad de procesamiento de $9,545.45 \mathrm{~kg}$, posee una tolva metálica con una capacidad de 1,363.63 kg. En este modelo se utiliza despulpadora 
marca Eterna de tres boquillas, cilindro horizontal con camisa de cobre, con un motor de $3.5 \mathrm{hp}$.

La cantidad de agua que se utiliza para el lavado de un quintal de café oro es de $1.09 \mathrm{~m}^{3}$, siendo una cantidad aceptable ya que está por debajo de los estándares nacionales del consumo de agua que es de máximo de $2 \mathrm{~m}^{3}$ por qq oro según la norma técnica ambiental para la protección de los cuerpos de agua afectado por los vertidos líquidos y sólidos proveniente de los beneficios húmedos de café NTON 05 028-06.

No se realiza reutilización del agua debido a que no poseen infraestructura adecuada para el almacenamiento de agua del último lavado que es la que posee un menor grado de contaminación.

El agua proveniente del lavado del café fermentado es depositada en fosas comunes cavadas en la superficie del terreno con una profundidad de $1 \mathrm{~m}^{2}$, éstas son ubicadas de manera consecutiva para que el agua se filtre a través de la arena y el piedrín que se encuentra en el fondo de las fosas.

Con respecto a los desechos sólidos que se producen en este beneficio no reciben ningún tratamiento, debido a que no posee pulperos o lugar de tratamiento, lo que hacen es recogerlos en sacos macen y luego los trasladan a las plantaciones de café y los distribuyen para que se desintegre y sea absorbido por la planta.

\section{Caracterización del beneficio "El Viajero"}

La Finca "El Viajero" está ubicada en la Comunidad la Vencedora No. 2, a una altitud de $950 \mathrm{msnm}$, con un área total de beneficio de $130 \mathrm{~m}^{2}$. Las variedades con las que cuentan son Catimor y Caturra. El tipo de beneficio colectivo y pertenece a la cooperativa "El progreso".

El beneficio cuenta con un pulpero, un canal de correteo, dos pilas de fermentación de concreto con una capacidad de procesamiento de $4,363 \mathrm{~kg}$, una pila de recepción del café uva cuya capacidad es $1,363 \mathrm{~kg}$. Las áreas son techadas.

La pila de almacenamiento de agua está a una distancia de 100 metros de la fuente, en una parte inclinada que ayuda a que el agua llegue al beneficio impulsado por la fuerza da gravedad. El volumen de la pila es $9 \mathrm{~m}^{3}$.

La cantidad de agua que se utiliza para el lavado de un quintal de café oro es de 1.2 $\mathrm{m}^{3}$ siendo aceptable ya que no excede los estándares nacionales del consumo de agua que es de un máximo de $2 \mathrm{~m}^{3}$ por qq oro según NTON 05 028-06.

Las aguas mieles van las fosas de tratamiento lo que se hace en este proceso es dejarlas que poco a poco se vallan filtrando al suelo. Estas pilas no poseen la capacidad adecuada para el almacenamiento de toda el agua que produce el beneficio, lo que dificulta el manejo adecuado. 
Los desechos sólidos son utilizados como abono orgánico para el café en la plantación y en los viveros. A la pulpa de café se le agrega cal y se está removiendo cada 15 días con el objetivo de prevenir malos olores y disminuir la humedad.

\section{Caracterización del beneficio "San Antonio"}

La finca "San Antonio" pertenece a la Cooperativa "La Flor Número Uno" y está ubicada en la Comunidad "San Francisco de los Cedros", a una altura de 1005 $\mathrm{msnm}$ y posee un área total de beneficio de $104 \mathrm{~m}^{2}$. Las variedades de café son Caturra Estrella y Catimor.

El beneficio tiene una capacidad de procesamiento de $2,045.45 \mathrm{~kg}$, posee una tolva de madera, una despulpadora marca Eterna de tres boquillas, cilindro horizontal con una camisa de cobre, con un motor de $3.5 \mathrm{hp}$, además de tres pilas de fermentación con medidas de $10.20 \mathrm{~m}$ de largo por $0.95 \mathrm{~m}$ de ancho y una profundidad de $1 \mathrm{~m}$, con un orificio de salida de 2 pulgadas y una pila de $1 \mathrm{~m}^{2}$ para la recepción del mucílago.

A los desechos líquidos no se les realiza ningún tratamiento, ya que las aguas provenientes del lavado y de otras actividades son depositadas en un pequeño crique que pasa cerca del beneficio, lo que desfavorece al factor ambiental.

Este beneficio carece de pulpero para el almacenamiento y tratamiento del residuo sólido.

\section{Caracterización del beneficio finca "La Florida"}

La finca "La Florida" está ubicada en la comunidad "Vencedera Arriba", a una altura de $961 \mathrm{msnm}$ y posee un área total de beneficio de $110 \mathrm{~m}^{2}$, del tipo industrializado, ver figura 1. Las variedades de café presentes son Caturra, Maragojipe y Catimor.

La capacidad de procesamiento de este beneficio es de 1,000 latas por hora. Posee pilas de recepción de café, conectado a través de tuberías de diámetros de 4 pulgadas a una pequeña pila de 3 metros de largo por 2 metros de ancho llamada pila de relevo, la cual es utilizada para la recepción del agua que se va a reutilizar en el proceso de trasporte del café uva

Las aguas mieles se envían a las pilas de depuración y evaporación por medio de un sistema de bombeo, estas pilas son de concreto, en las cuales se depositan las aguas mieles para su filtración y así lograr separar la materia orgánica para disminuir la carga contaminante. Durante el finca "La Florida"

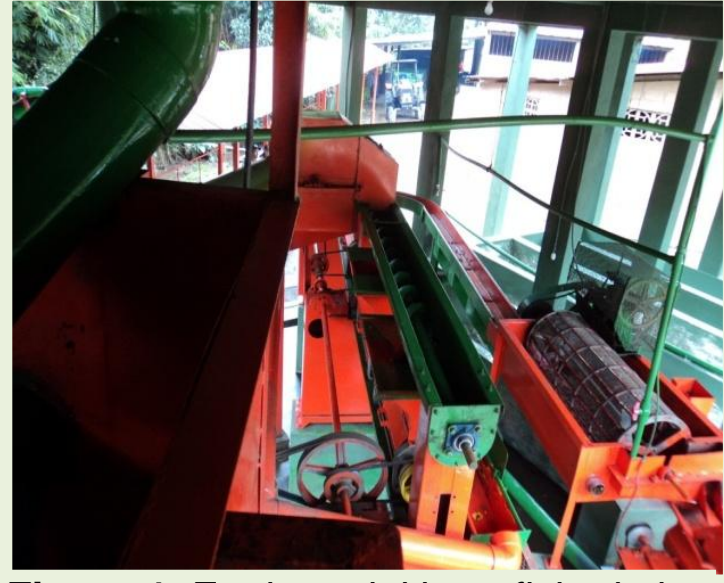

Figura 1. Equipos del beneficio de la 
tratamiento se aplica manualmente cal viva para neutralizar los niveles de acidez.

Los pulperos están ubicados a unos 400 metros de la fuente de agua más cercana, en la parte céntrica de las plantaciones de café. Uno tiene un área de $40 \mathrm{~m}^{2}$ que abarca el $80 \%$ y el otro de $20 \mathrm{~m}^{2}$ con el $20 \%$. Estos se encuentran al aire libre donde la pulpa se descompone por factores naturales como: el sol, viento y temperaturas.

\section{Conclusiones}

Los beneficios colectivos estudiados estaban ubicados a altitudes de 950 a 1005 msnm, con dimensiones de construcción aproximado de 104 a $140 \mathrm{~m}^{2}$. Estos utilizan un máximo de 5 hombres para el proceso de beneficiado, el agua que se utiliza para el lavado proviene de pequeñas quebradas, criques y ojos de agua. Para el tratamiento de los desechos utilizan áreas destinadas para el almacenamiento.

El consumo de agua de los beneficios húmedos estudiados la cantidad de agua que utilizan para el lavado de un quintal de café oro oscila entre 1.09 a $1.50 \mathrm{~m}^{3}$ de agua que está por debajo de los estándares que indica la NTON 05 028-06 que señala el consumo máximo para procesar un quintal oro es de $2 \mathrm{~m}^{3}$ de agua.

Los principales impactos de más afectaciones al medio ambiente son: contaminación del suelo, el agua de ríos, ojos de agua, para estos se deben tomar medidas correctivas para minimizar el impacto que provocan al medio ambiente, dentro de la propuesta que deben tomarse en cuenta, mejorar y construir áreas específicas para el depósito de desechos sólidos y líquidos en lugares donde no afecta la salud de la población, así mismo se debe tomar en cuenta el consumo de agua, es la principal contaminación y escasez que tienen los beneficios estudiados ya que estos tienen poca agua disponible para el lavado del café.

\section{Referencias}

Dicovskiy, L. M. (2009). Situación actual del cultivo de caféen las Segovias, con énfasis en el estado de la cosecha en finca y la calidad. Estelí .

IICA. (2008). Recuperado el 7 de sep de 2011, de http://webiica.iica.ac.cr/prensa/boletines/nicaragua/default.asp?boletin=Boleti n239\&num=239\#GuiaTecnica

JICA, IICA, MAGFOR,. (2004). Cadena agroindustrial del café. Managua. 